\title{
HLA antigens in Omanis with blinding trachoma: markers for disease susceptibility and resistance
}

Arthur G White, Jorn Bogh, William Leheny, Padmavathi Kuchipudi, Mathew Varghese, Hamad Al Riyami, Sulieman Al Hashmi, Abdallah S Daar

\begin{abstract}
Aim-To determine the presence of HLA antigens in people with blinding trachoma.

Methods-Fifty Omanis with blinding trachoma were serologically typed for HLA $A, B, C, D R$, and DQ antigens and DNA typed for class II DR $\beta$ and DQ $\beta$ alleles and compared with a population of 100 healthy controls.

Results- $\chi^{2}$ analysis of serological reactions did not reveal any significant differences in HLA antigen frequencies after correction of probability, although DR4, DR7, and DR53 were completely absent in the patients and all of the patients were HLA DQ1 positive. In the case of DQ1 the relative risk was 22.6 (95\% confidence interval of 20.7-24.7). Class II DNA low resolution DR $\beta$ typing showed a significant increase in HLA DR16 $\left(p_{c}=0.036\right.$, relative risk $=3.8$ ) and a significant decrease in HLA DR53 $\left(p_{c}=0.018\right.$, relative risk $=0.05$ ).
\end{abstract}

Conclusion-The finding that HLA DR16 (a DR2 subtype) is associated with susceptibility to blinding trachoma, a disease that is caused by an intracellular microorganism, is consistent with reports of an HLA DR2 association with leprosy and tuberculosis, diseases also caused by an intracellular micro-organism. Similarly, resistance to leprosy is associated with HLA DR53 as is the case with blinding trachoma described here. It is postulated that HLA DR2 or subtypes in association with HLA DQ 1 may enable an intracellular micro-organism to enter the cell or are involved in presentation of peptides derived from intracellular micro-organisms to $T$ lymphocytes initiating a delayed hypersensitivity or autoimmune reaction. These findings are the first report that genetic factors are of major importance in the development and protection against blinding trachoma.

(Br f Ophthalmol 1997;81:431-434)

Trachoma is a disease that actively affects at least 500 million individuals worldwide. At least two million of these people are blind from trachoma with many more having a significant visual handicap. ${ }^{1}$ It is the second most common cause of blindness after cataract. ${ }^{2}$ It is initiated by repeated infections with Chlamydia trachomatis and in endemic areas it is an infectious disease of early childhood, promoted by low socioeconomic status with deficient community and personal hygiene. Most children are infected by the age of 1-2 years and from the age of 5 years the number of detectable $C$ trachomatis positives declines steadily. A significant number of these children show no inflammatory reaction and the eyes appear normal. ${ }^{3}$ In later childhood and in adults, infectious and inflammatory disease becomes less prevalent, and in a large proportion of these no $C$ trachomatis can be detected even using the polymerase chain reaction to amplify chlamydial DNA. ${ }^{4}$ Even in the later stages of trachoma, which are characterised by trichiasis and corneal opacities, demonstration of $C$ trachomatis is the exception. The finding of infection without disease and disease without infection suggests that the immune response to the infection may determine the clinical status. ${ }^{5}$ Infections with $C$ trachomatis are self limiting but repeated reinfections from the environment give the disease its apparent chronicity. After each infection the organism is cleared and the persistent clinical response may be a delayed hypersensitivity reaction directed against residual $C$ trachomatis antigens, resulting in prolonged inflammation. Furthermore, inflammatory trachoma has several factors that are also common to organ specific autoimmunity. The expression of MHC class II antigens by the conjunctival epithelium in inflammatory trachoma has been reported. ${ }^{6}$

The clinical picture of trachoma varies from a very mild condition with hardly any symptoms to a severe and blinding disease. ${ }^{1}$ Within a community there may be striking differences between families in the prevalence and severity of disease. ${ }^{3}$ The degree of inflammatory immune response appears to be partly host determined, since even in areas where trachoma is holoendemic, only a subset of individuals develop severe scarring of the upper conjunctiva with trichiasis and corneal opacities leading to blinding trachoma. ${ }^{7}$ This
Accepted for publication 13 January 1997 
Table 1 Significant associations with and without probability correction of HLA serologically detected antigens in patients with blinding trachoma

\begin{tabular}{|c|c|c|c|c|c|c|c|c|}
\hline \multirow[b]{2}{*}{$H L A$ antigen } & \multicolumn{2}{|c|}{$\begin{array}{l}\text { Blinding } \\
\text { trachoma }(n=50)\end{array}$} & \multicolumn{2}{|c|}{ Controls $(n=100)$} & \multirow[b]{2}{*}{$R R$} & \multirow[b]{2}{*}{$\chi^{2}$} & \multirow[b]{2}{*}{$p$ Value } & \multirow[b]{2}{*}{$p_{c}^{*}$} \\
\hline & pos & neg & pos & neg & & & & \\
\hline HLA-A30 & 1 & 49 & 19 & 81 & 0.12 & 7.33 & 0.007 & 0.4235 \\
\hline HLA-A 32 & 16 & 34 & 17 & 83 & 5.17 & 4.37 & 0.037 & 2.2570 \\
\hline HLA-DR2 & 46 & 4 & 73 & 27 & 3.86 & 6.76 & 0.009 & 0.5654 \\
\hline HLA-DR4 & 0 & 50 & 11 & 89 & 0.07 & 5.89 & 0.015 & 0.8912 \\
\hline HLA -DR7 & 0 & 50 & 8 & 92 & 0.10 & 4.34 & 0.035 & 2.1319 \\
\hline HLA-DR53 & 0 & 50 & 15 & 85 & 0.05 & 7.72 & 0.006 & 0.3483 \\
\hline HLA-DQ1 & 50 & 0 & 82 & 18 & 22.64 & 8.97 & 0.003 & 0.1933 \\
\hline
\end{tabular}

${ }^{\star} \mathrm{p}_{\mathrm{c}}=$ probability $\times$ no of comparisons $(79)$.

evidence may indicate that there is a genetic susceptibility in individuals who develop blinding trachoma. Antigens of the major histocompatibility complex (MHC) have been reported to be associated with a broad spectrum of human disease and in particular diseases associated with aberrant immunity. We could find only one other report in the literature that looked at the frequency of human leucocyte antigens (HLA) in trachoma. ${ }^{8}$

This report describes the frequency of HLA antigens in Omanis with blinding trachoma.

\section{Material and methods}

Fifty patients with blinding trachoma defined by the presence of trachomatous trichiasis and corneal opacities in accordance with the WHO 1987 trachoma grading system ${ }^{9}$ were typed for HLA antigens. All patients were examined and identified by the same consultant.

The frequency of HLA antigens in these patients was compared with 100 Omani controls for detection of HLA class I and II antigens by serology and class II DR $\beta 1$ and DQ $\beta 1$ by DNA analysis. The Omani controls were healthy volunteer blood donors, university students, potential kidney or bone marrow donors. These donors, like the patients with blinding trachoma, came from all parts of Oman, and were considered ethnically representative of the normal population. None of the patients or donors were related.

For serological HLA-ABC and DR typing 15-20 $\mathrm{ml}$ of blood taken into EDTA was used. Lymphocytes were separated by density gradient centrifugation and then the class II positive cells (predominantly B lymphocytes) separated using magnetic beads (Dynabeads, Dynal, Skoyen, Norway). The supernatant containing $\mathrm{T}$ cells was used for ABC typing and the purified $B$ cells for DR (class II) typing. HLA typing was performed using a modified two stage cytotoxicity technique with ethidium bromide/acridine orange staining and observation with a semiautomated fluorescent microscope. ${ }^{10}$

The following serological specificities could be determined (79 in total):

A locus: 1, 2, 3, 9, 10, 11, 19, 23, 24, 25, 26, $28,29,30,31,32,33,34,36$.

B locus: 5, 7, 8, 12, 13, 14, 15, 16, 17, 18, 21, $22,27,35,37,38,40,41,42,44,45,48,49$, $50,51,52,53,55,57,60,61,62$, Bw4, Bw6.

C locus: w1, w2, w3, w4, w5, w6.

DR locus: $1,2,3,4,5,6,7,8,9,10,11,12$, 14, 15, DRw52, DRw53.
DQ locus: 1, 2, 3, 7 .

For class II DNA typing, the DNA was extracted from $2 \mathrm{ml}$ of EDTA blood using either a commercial kit (Nucleon, Scotlab, UK) or a local method using a rapid mini salting out technique based on that described by Miller et al. ${ }^{11}$ The separated DNA was amplified in a thermal cycler, following the manufacturer's instructions, with class II primers defining DR $\beta 1$ and DQ $\beta 1$ (Dynal low resolution SSP, Dynal, Skoyen, Norway) together with PCR buffer, taq polymerase, and DNA nucleotides (Gibco BRL, Paisley, UK). The products were run on $1.2 \%$ agarose gels containing ethidium bromide, examined under ultraviolet illumination, and the class II specificities identified. The following DR and DQ specificities could be determined (32 in total).

DNA DR: $1,2(15,16), 3(17,18), 4,5$

$(11,12), 6(13,14), 7,8,9,10$.

DRw: 51,52 , and 53 .

DNA DQ: $1(5.1,5.2,5.3,6.1,6.2,6.3,6.4$, $6.7,6.9)$

$2(2.1,2.2)$.

$3(3.1,3.2,3.3,3.4,3.5)$.

$4(4.1,4.2)$

Statistical analysis was carried out using the $\chi^{2}$ test or the Fisher's exact test depending on the numbers involved. The probability was corrected for the number of comparisons made using the Bonferroni correction, obtained by multiplying the number of antigens tested for (79 for serology and 18 for class II DNA DR $\beta 1$, and 14 for DNA DQ $\beta 1$ ) to correct for any chance associations $\left(\mathrm{p}_{\mathrm{c}}\right)$. $^{12}$ The strength of the association was estimated by calculation of the relative risk (RR) using Haldane's modification for small numbers when appropriate. ${ }^{13}$ The $95 \%$ confidence intervals (CI) of the relative risk were calculated using the method based on the logarithm of the standard error with reference to a normal distribution. ${ }^{14}$

It should be emphasised that the calculation of relative risk can be misleading when the numbers of positives/negatives in both patients and controls are low.

\section{Results}

The class I and class II results determined by serology that reached statistical significance using $\chi^{2}$ analysis (uncorrected probability) are shown in Table 1 together with the corrected probabilities.

In relation to HLA serology none of the antigens were significantly associated with blinding trachoma using $\chi^{2}$ analysis, when the probability was corrected. However, calculation of relative risk, when adequate numbers were available, showed that susceptibility was associated with HLA-A32 (RR $=5.17,95 \%$ CI 2.86 to 9.34$), \mathrm{DR} 2(\mathrm{RR}=3.86,95 \%$ CI 3.35 to 4.45 ), and DQ1 ( $R R=22.6,95 \%$ CI 20.72 to 24.69). Resistance to trachoma was associated with HLA-A30 (RR $=0.12,95 \%$ CI 0.02 to 0.87 ), DR4 (RR $=0.07,95 \%$ CI 0.009 to $0.53)$, DR7 ( $R R=0.10,95 \%$ CI 0.01 to 0.78$)$, and DR53 (RR $=0.05,95 \%$ CI 0.006 to 0.35 ).

All the class II results for DNA DR $\beta 1$ and DQ $\beta 1$ are shown in Tables 2 and 3. DNA typing revealed that the DR16 split of DR2 was 
Table 2 Class II DNA HLA DR $\beta 1$ in trachoma patients and controls

\begin{tabular}{|c|c|c|c|c|c|c|c|c|}
\hline \multirow[b]{2}{*}{ DR antigens } & \multicolumn{2}{|c|}{$\begin{array}{l}\text { Trachoma patients } \\
(n=46)\end{array}$} & \multicolumn{2}{|c|}{$\begin{array}{l}\text { Controls } \\
(n=100)\end{array}$} & \multirow[b]{2}{*}{$R R$} & \multirow[b]{2}{*}{$\chi^{2}$} & \multirow[b]{2}{*}{$p$ Value } & \multirow[b]{2}{*}{$p_{c}$} \\
\hline & pos & neg & pos & neg & & & & \\
\hline DR1 & 2 & 44 & 2 & 98 & 2.21 & 0.68 & 0.794 & 14.292 \\
\hline DR103 & 0 & 46 & 0 & 100 & - & - & - & - \\
\hline \multicolumn{9}{|l|}{ DR2: } \\
\hline combined & 42 & 4 & 72 & 28 & 3.71 & 6.86 & 0.009 & 0.162 \\
\hline 15 & 6 & 40 & 22 & 78 & 0.56 & 1.63 & 0.202 & 3.636 \\
\hline 16 & 39 & 7 & 58 & 42 & 3.82 & 10.14 & 0.002 & $0.036^{\star}$ \\
\hline \multicolumn{9}{|l|}{ DR3: } \\
\hline 17 & 16 & 30 & 27 & 73 & 1.44 & 0.92 & 0.338 & 6.084 \\
\hline 18 & 1 & 45 & 2 & 98 & 1.30 & 0.005 & 0.945 & 17.010 \\
\hline DR4 & 0 & 46 & 13 & 87 & 0.07 & 6.56 & 0.011 & 0.198 \\
\hline \multicolumn{9}{|l|}{ DR5: } \\
\hline 11 & 5 & 41 & 13 & 87 & 0.86 & 0.13 & 0.716 & 12.888 \\
\hline 12 & 0 & 46 & 1 & 99 & 0.71 & 0.46 & 0.469 & 8.928 \\
\hline \multicolumn{9}{|l|}{ DR6: } \\
\hline 13 & 1 & 45 & 8 & 92 & 0.36 & 1.85 & 0.175 & 3.150 \\
\hline 14 & 2 & 44 & 0 & 100 & 11.30 & 0.65 & 0.420 & 7.560 \\
\hline DR7 & 0 & 46 & 7 & 93 & 0.13 & 3.38 & 0.067 & 1.206 \\
\hline DR8 & 0 & 46 & 1 & 99 & 0.71 & 0.46 & 0.496 & 8.928 \\
\hline DR9 & 0 & 46 & 0 & 100 & - & - & - & - \\
\hline DR10 & 2 & 44 & 3 & 97 & 1.09 & 0.17 & 0.678 & 12.204 \\
\hline DR51 & 42 & 4 & 69 & 31 & 4.30 & 8.60 & 0.004 & 0.072 \\
\hline DR52 & 24 & 22 & 46 & 54 & 1.27 & 0.48 & 0.607 & 10.926 \\
\hline DR53 & 0 & 46 & 16 & 84 & 0.05 & 10.66 & 0.001 & $0.18^{\star}$ \\
\hline
\end{tabular}

^Statistically significant.

Table 3 Class II DNA/HLA DQ $\beta 1$ typing of trachoma patients and controls

\begin{tabular}{|c|c|c|c|c|c|c|c|c|}
\hline \multirow[b]{2}{*}{ HLA antigen } & \multicolumn{2}{|c|}{$\begin{array}{l}\text { Trachoma patients } \\
(n=46)\end{array}$} & \multicolumn{2}{|c|}{$\begin{array}{l}\text { Controls } \\
(n=100)\end{array}$} & \multirow[b]{2}{*}{$R R$} & \multirow[b]{2}{*}{$\chi_{2}$} & \multirow[b]{2}{*}{$p$ Value } & \multirow[b]{2}{*}{$p_{c}$} \\
\hline & pos & neg & pos & $n e g$ & & & & \\
\hline $\mathrm{DQB}^{\star} 0501$ & 5 & 41 & 13 & 87 & 0.86 & 0.132 & 0.716 & 10.020 \\
\hline $\mathrm{DQB}^{\star} 0502$ & 38 & 8 & 63 & 37 & 2.67 & 5.682 & 0.018 & 0.252 \\
\hline $\mathrm{DQB}^{\star} 0503$ & 2 & 44 & 1 & 99 & 3.72 & $\star$ & 0.234 & 3.276 \\
\hline $\mathrm{DQB} \mathrm{B}^{\star} 0601$ & 2 & 44 & 8 & 92 & 0.61 & * & 0.506 & 7.084 \\
\hline $\mathrm{DQB}^{\star} 0602$ & 4 & 42 & 8 & 92 & 1.15 & $\star$ & 0.558 & 7.812 \\
\hline $\mathrm{DQ}^{\star} \mathrm{B}^{\star} 0603 / 0607$ & 3 & 43 & 5 & 95 & 1.40 & * & 0.488 & 6.832 \\
\hline $\mathrm{DQB}^{\star} 0604 / 0609$ & 1 & 45 & 2 & 98 & 1.30 & $\star$ & 0.682 & 9.548 \\
\hline $\mathrm{DQB}^{\star} 0201 / 0202$ & 14 & 32 & 27 & 73 & 1.19 & 0.184 & 0.668 & 9.352 \\
\hline DQB`0301 & 2 & 44 & 11 & 89 & 0.44 & $\star$ & 0.159 & 2.226 \\
\hline $\mathrm{DQB}^{\star} 0302$ & 0 & 46 & 8 & 92 & 0.12 & * & 0.044 & 0.616 \\
\hline $\mathrm{DQB}{ }^{\star} 0303$ & 1 & 45 & 1 & 99 & 2.20 & $\star$ & 0.532 & 7.448 \\
\hline $\mathrm{DQB}^{\star} 0304$ & 1 & 45 & 0 & 100 & 6.62 & * & 0.315 & 4.410 \\
\hline $\mathrm{DQB}^{\star} 0401$ & 0 & 46 & 0 & 100 & 2.16 & - & - & - \\
\hline $\mathrm{DQB}^{\star} 0402$ & 1 & 45 & 3 & 97 & 0.92 & $\star$ & 0.625 & 8.750 \\
\hline
\end{tabular}

ॠWhen numbers are small Fisher's exact test applied.

significantly associated with susceptibility to blinding trachoma $\left(\mathrm{p}_{\mathrm{c}}=0.036, \mathrm{RR}=3.82\right.$, $95 \%$ CI 3.11 to 4.69 ) and DR53 with resistance to the disease $\left(\mathrm{p}_{\mathrm{c}}=0.018, \mathrm{RR}=\right.$ $0.05,95 \%$ CI 0.01 to 0.36 ).

In our study, analysis of the frequency of A28 showed an increase in patients $(\mathrm{p}=0.037)$ but this was not significant after appropriate correction $\left(\mathrm{p}_{\mathrm{c}}=2.275\right)$.

The HLA association, determined by serological typing, in terms of relative risk, for DR2, DR4, DR7, and DR53 was confirmed by DNA typing.

\section{Discussion}

To our knowledge there is only one other report in the literature that has looked at the frequency of human leucocyte antigens (HLA) in trachoma. ${ }^{8}$ These authors looked at HLA frequencies in Gambian patients with eyelid scarring. Our patients had more advanced disease in that they had gone on to develop corneal opacification, fitting with the WHO classification for 'blinding trachoma'. The Gambian study found an association of the disease with a subtype of the HLA A28 antigen (HLA $A^{\star} 6802$ ). In our study A28 was not sig- nificantly associated with blinding trachoma. We do not know if the patients in our study are comparable with those in the Gambian study and there remains the possibility that the HLA frequencies reported in our study are related specifically to corneal opacification and hence blindness. The other possibility is that the differences may be due to differences in ethnic background.

We have demonstrated a significant association of HLA DR16 (DR2) with susceptibility $(\mathrm{RR}=3.82)$ and $\mathrm{DR} 53$ with protection against the disease $(R R=0.05)$. HLA DR53 is in linkage disequilibrium with both DR4 and DR7, leading to a decrease in both of these antigens although this did not reach statistical significance.

The role of HLA antigens in protection from disease merits further comment. There are two clear examples from the literature. HLA-DR2 and DQ6 (in linkage disequilibrium with DR $\beta$ genes encoding DR2) have been reported to protect from type 1 diabetes. This HLA associated protection is dominant with a relative risk of 0.02 . Thus, type 1 diabetes rarely develops in DR2/DQ6 individuals. ${ }^{15}$

Protection from severe malaria is reportedly associated with HLA-Bw53. ${ }^{16}$ HLA-Bw53 was demonstrated in $15.7 \%$ of patients with severe malaria compared with $24.3 \%$ in mild malaria controls and $25 \%$ in healthy adults. The uncorrected probability was $\mathrm{p}=0.04$-if corrected by multiplying by the numbers of antigens tested for ( 45 for class I) the results would have been clearly statistically insignificant $\left(p_{c}=1.8\right)$ with a relative risk of 0.59 . The data presented here clearly show that HLA DR53 is significantly associated with protection from blinding trachoma $\left(\mathrm{p}_{\mathrm{c}}=0.018\right)$ and a relative risk of 0.05 .

Perhaps more interestingly HLA DR16, a subtype of DR2 defined in this study by DNA, is significantly associated with susceptibility to blinding trachoma. It is worth drawing attention to the fact that two other diseases caused by an intracellular micro-organism-namely, leprosy ${ }^{17-19}$ and tuberculosis, ${ }^{120}$ have been reported to be associated with HLA DR2 or its subtypes. In two of these papers, ${ }^{18}{ }^{19}$ HLA DQ1 was also significantly associated with leprosy and tuberculosis. All the patients in our study were HLA DQ1 positive with a relative risk of 22.6 (95\% CI 20.72 to 24.69 ).

It is conceivable that HLA DR2 (DR15/ DR16) and/or DQ1 is a receptor for certain microbial antigens and is a portal for entry of intracellular infections or is responsible for presentation of antigenic peptides derived from intracellular pathogens to the $\mathrm{T}$ cell receptor. HLA class II expression has been demonstrated in conjunctival biopsies in patients with active trachoma. ${ }^{61}$ Thus, these epithelial cells are potentially able to present chlamydial antigens to $\mathrm{T}$ cells and potentiate what may become an autoimmune disease or a delayed hypersensitivity reaction.

Furthermore, in Japanese patients with leprosy $^{17}$ HLA DR53 was significantly decreased in the patients, supporting our own finding that HLA DR53 is absent in patients 
and may significantly protect from blinding trachoma.

It is possible that HLA DR16 and DQ1, in the absence of DR53, may be part of an antigen presenting complex resulting in blinding trachoma.

To quote from Dawson et $a l^{3}$ 'Within a community there may be striking differences, between families, in the prevalence and severity of the disease. These variations appear to be intimately related to environmental and behavioural factors'. We can now add 'genetic factors' to this quotation and help to explain some of the enigmas of this disease.

Since this manuscript was submitted a report on HLA in patients with trachomatous scarring of the eyelid, but not blinding trachoma, has been published.

1 Sanford-Smith J. In: Eye diseases in hot climates. Bristol: Wright, 1986;7:80-92.

2 Mabey D, Mabey D. New hope for trachoma control. Com munity Eye Health 1994;7:17-8.

Dawson CR, Jones BR, Tarizzo ML Guide to trachoma control. Geneva: WHO, 1981;3:22

4 Bobo L, Munoz B, Viscidi R, Quinn T, Mkocha H, West S. Diagnosis of Chlamydia trachomatis eye infection in Tanzania by polymerase chain reaction/enzyme immunoassay. Lancet 1991;338:847-50.

5 Taylor HR, Rapoza PA, West S, Johnson S, Munoz B, Katala $\mathrm{S}$, et al. The epidemiology of infection in trachoma. Invest Ophthalmol Vis Sci1989;30:1823-33.

6 Mabey DCW, Bailey RL, Dunn D, D Jones, Williams JHD, Whittle HC, et al. Expression of MHC Class II antigens by conjunctival epithelial cells in trachoma: implications concerning the pathogenesis of blinding disease. 7 Clin Pathol 1991;44:285-9.

7 Courtright P, Lewallen S, Howe R. Cell-mediated immunity in trachomatous scarring. Evidence from a leprosy population. Ophthalmology 1993;100:98-104.
8 Conway DJ, Holland MJ, Campbell AE, Bailey RL, Krausa $\mathrm{P}$, Peeling RW, et al. HLA class I and II polymorphisms and trachomatous scarring in a Chlamydia trachomatisendemic population. F Infect Dis 1996;174:643-6.

9 Thylefors B, Dawson CR, Jones BR, West SK, Taylor HR. A simple system for the assessment of trachoma and its complications. Bull WHO 1987;65:477-83.

10 Venkataram MN, White AG, Leheny WA, Suwaid AR, Daar AS. HLA antigens in Omanis with vitiligo. Clin Exp Derm 1995;20:35-7.

11 Miller SA, Dykes DD, Polesky HF. A simple salting out procedure for extracting DNA from human nucleated cells. Nucleic Acids Res 1988;16:1215-8.

12 Svejgaard A, Ryder LP. HLA and disease associations: detecting the strongest association. Tissue Antigens 1994;43: $18-27$.

13 Haldane JBS. The estimation and significance of the logarithm of a ratio of frequencies. Ann Hum Genet 1956;20:309-11

14 Altman DG. Practical statistics for medical research. 1st ed. London: Chapman and Hall 1991;266-8.

15 Thorsby E. HLA-associated disease susceptibility-which genes are primarily involved? Immunologist 1995;3:51-8.

16 Hill AVS, Allsopp CEM, Kwiatkowski D, Anstey NM, Twumasi P, Rowe PA, et al. Commom West African HLA antigens are associated with protection from severe malaria. Nature 1991;352:595-600.

17 Joko S, Numaga J, Fujino Y, Masuda K, Hirata R, Maeda H. HLA and uveitis in leprosy. Nippon Ganka Gakkai Zasshi 1995;99:1181-5.

18 Todd JR, West BC, McDonald JC. Human leucocyte antigen and leprosy: study in northern Louisiana and review. Rev Infect Dis 1990;12:63-74.

19 Mehra NK, Rajalingan R, Mitra DK, Taneja V, Giphart MJ. Variants of HLA-DR2/DR51 group haplotypes and susceptibility to tuberculoid leprosy and pulmonary tuberculosis in Asian Indians. Int $\mathcal{F}$ Leprosy Mycobact Disorders 1995;63:241-8.

20 Brahmajothi V, Pitchappan RM, Kakkanaiah VN, Sashidhar M, Rajaram K, Ramu S, et al. Association of pulmonary tuberculosis and HLA in south India. Tubercle 1991;72: 123-32.

21 El-Asrar AMA, Van Den Oord JJ, Geboes K, Missotten L, Emarah $\mathrm{MH}$, Desmet V. Immunopathology of trachomatous conjunctivitis. Br $\mathcal{F}$ Ophthalmol 1989;73:276-82. 